\title{
Developing an Estimate of Supported Housing Needs for Persons with Serious Mental Illnesses
}

\author{
Jeannette Waegemakers Schiff, ${ }^{1}$ Rebecca Schiff, ${ }^{2}$ and Barbara Schneider ${ }^{1}$ \\ ${ }^{1}$ University of Calgary, Calgary, AB, Canada T2N 1N4 \\ ${ }^{2}$ Memorial University, St. John's, NL, Canada A1C 5S7 \\ Correspondence should be addressed to Jeannette Waegemakers Schiff; schiff@ucalgary.ca
}

Received 26 July 2013; Revised 13 March 2014; Accepted 20 March 2014; Published 27 April 2014

Academic Editor: Alberto Davila

Copyright (C) 2014 Jeannette Waegemakers Schiff et al. This is an open access article distributed under the Creative Commons Attribution License, which permits unrestricted use, distribution, and reproduction in any medium, provided the original work is properly cited.

\begin{abstract}
A rich body of literature attests to the importance of affordable accommodation and support services necessary, appropriate, and acceptable to persons disabled by a mental illness. However, there is a little which provides a means for housing and service planners to determine the gap between available supportive housing and need. Such understandings are needed to prepare strategies and develop the resources needed to accommodate persons with a disabling mental illness in the community. While housing studies that examine shelter needs of the homeless acknowledge that a sizable proportion has a disabling mental illness, these numbers underestimate need in the cohort that experiences disabling mental illnesses. This underestimate exists because many of those who are disabled by mental illness and in need of supportive housing are among the hidden homeless: doubled-up, couch-surfing, and temporarily sheltered by friends and family. Thus, little is known about the size of this cohort or their supportive shelter needs. The present analysis examines two approaches and offers one methodology as most feasible and parsimonious which can approximate housing need and may be extrapolated to other urban locations.
\end{abstract}

\section{Introduction}

Persons who have a disabling mental illness are victims of disease and disability which creates challenges for their full participation in contemporary society. For many adults disabled by severe mental illness, living in the community is predicated on the availability of affordable, accessible, and appropriate housing with individualized and specialized supports [1-3]. Even with the best inpatient care, discharge into homelessness has been a too frequent reality for those who have no stable housing $[4,5]$. The result is poor health outcomes [6], increased involvement with the justice system, and an exacerbation of homelessness [7]. "Housing first" studies have shown that, with appropriate housing and supports, those with a disabling mental illness remain housed, even when there is concurrent substance misuse [810].

One of the great failures of the deinstitutionalization movement was the reality that hundreds of thousands of persons with a serious mental illness were discharged into the community with no planning for their housing and continuing care needs $[11,12]$. Since the 1980's many studies have examined the types of housing and supports necessary for community living [13]. In contrast, almost no research examines how many persons who have a mental health disability need supported housing (rental supplements and instrumental supports) in order to assure safe and stable community tenure. Additionally, housing planners also fail to take these needs into account [14].

Housing loss is often reported to be the result of a combination of lack of financial affordability and lack of acceptable supports [15]. A fundamental approach to assessing this need is a determination of the prevalence of persons with serious and persistent mental illnesses, the extent of those whose mental illness includes persistent functional disabilities (whom we describe as persons with MID) [16], and the resultant need for supportive housing. Because there is no evidence about the length of time that those with a MID will need supports with both housing and other aspects of daily life, planning must be ongoing, rather than occasional. 
Without accurate estimates of the magnitude of this need, public health, housing, and mental health services systems continue to be unable to plan for, or provide, the necessary levels of community-based supported living units and the resultant social and health disruptions reported for those who lose housing will continue.

Prevalence estimates for those with various psychiatric diagnoses, such as schizophrenia and bipolar disorder, fail to capture the prevalence of those with major depression and a variety of other less common psychiatric disorders that result in functional disabilities. These disabilities include the ability to retain full-time competitive employment and live independently with no social and instrumental supports. Data on those who were deinstitutionalized is dated and does not account for the current population of people with MID who receive acute care locally and require community-based housing and supports. While there is no definitive literature on what type of housing would be required (i.e., independent, with supports, and intensive supervised), there is a growing body of evidence that housing with supports is critical to stability [8]. It is also suggested that persons with MID require a combination of supports unique to this population and different from other groups who might require supportive housing. Thus information about community-wide housing needs for persons with MID is of critical importance to mental health, social services, and housing planners.

As it is important to plan for roads, schools, and hospitals in modern and growing communities, so too must planners include various forms of housing, including that required by persons with disabilities. Wong [14] notes that the movement to include social indicators in the planning process fell into disarray in the 1980's due to the lack of reliable metrics to aid planners (Chapter 1) and in part due to the lack of interest by policy makers in including indicators not in political favor. This has led to the development, described below, of a synthetic analysis of the total housing needs (supports included) for persons with MID. The calculations we propose are based on prevalence studies applicable across North America and Europe which concur on prevalence rates for psychiatric disorders and can therefore be applied across those urban locations and adjusted to accommodate population growth.

\section{Housing Needs for People with Severe Mental Illness}

Housing without subsidies is unaffordable for those disabled by a mental illness (MID) as, in most cases, they are unable to hold competitive, full-time employment and rely on disability payments, federal, and/or state (provincial) to meet the needs of daily living. This also creates an inability to afford marketrate rental housing units as these income support programs do not, as explained below, reflect the realistic cost of living. Reliance on government subsidies for housing allowances is one way in which this need is addressed.

The commonly accepted income standard is the rule that no more than one third of monthly income should be required for housing (mortgage or rent). A disabled person, unable to work full-time, if at all, is eligible for disability benefits ranging, by province, from a low of $\$ 720$ per month in New Brunswick to a high of \$1535 in the Yukon. In the United States, supplemental security income (SSI) provides $\$ 710$ per month for an individual. This amount is supplemented in different amounts by most states and ranges from $\$ 60$ to $\$ 360$ per month for an individual [17]. Using the one third rule, a person with a MID can afford to pay between $\$ 236$ and \$510 per month for a place to live, depending on geographic location. In Alabama average rents are in the range of $\$ 700$ per month while in Alberta and Alaska they are $\$ 995$ (2013 rates). The gap between income and affordability of accommodation for those living on disability income is extraordinary.

A large component of the vast literature on housing for persons with MID examines the type of accommodation that is necessary, helpful, and acceptable for people diagnosed with severe mental illness $[18,19]$. Many studies examine these issues in the context of homelessness or near homelessness [20-22]. Some [23-25] report on the service and treatment needs of people diagnosed with a severe mental illness. Others [26, 27] discuss housing allocation, focusing on defining the parameters to determine individual need and eligibility. Many examine consumer housing satisfaction [19, $28,29]$ or cost effectiveness [30, 31] and housing retention outcomes [32-34].

Housing gaps $[35,36]$ are addressed in the context of studies that examine homeless shelter needs, based on the total homeless population in a given locality, and are unable to give precise estimates of need for persons with MID $[35,37]$. Most studies assume that psychosocial supports accompany accommodation. Throughout this analysis we make the same assumption that housing need includes income and other supportive services.

Critical evaluation of planning processes for housing needs for special populations has appeared in the literature as far back as 1978 with Heumann's [38] critique of the use of local secondary data to estimate local housing needs. Randolph and colleagues [27] presented a methodology for a state-wide assessment of housing needs but focused on residential beds for those in active treatment, as identified by service providers [39]. Canadian prevalence rates have to date relied on a couple of regional reports on schizophrenia, but the Public Health Agency of Canada relies on rates of other disorders from American data [12].

Recent efforts to establish housing need for those with a disabling mental illness indicate a heavy reliance on the National Household Survey on Drug Abuse [40]. This SAMSHA survey provides incidence data on serious mental illness but, since it excludes those in institutions (e.g., hospitals and jails), is an underestimate of true prevalence [41]. Local reports $[42,43]$ rely on the records of local mental health authorities and exclude people not currently receiving treatment or availing themselves of nonprofit agencies and private counselling services. A systematic analysis of the overall housing needs specifically of the mentally ill population in a given geographic area, regardless of where they currently reside, does not appear to exist as there is no reported methodology that permits an estimate of persons 
with MID for a given locality. Without such a calculation it is impossible to determine the gap between existing service and real need. The methodology that we recommend is based on the following anchor points: a precise count of persons with schizophrenia, a precise count of supportive housing units available, and well-documented levels of disability for specific psychiatric diagnoses.

\section{Background}

A study that produced an exact count of the number of supported housing units 1550-in Calgary, a western Canadian city of approximately one million [37], provided an anchor for this assessment process. Concurrent work by Benzins and Guyn, [44] identified the number of people diagnosed with schizophrenia in this region to be 6841. Extrapolated to the adult population this produces a rate of .009 , which approximated national prevalence rate reported at .010 [45]. As there is considerable agreement that schizophrenia causes disability (e.g., [46, 47], these numbers suggested a significant gap between housing availability and need). Because Calgary has a unified health system, with all known persons with a diagnosis of schizophrenia treated at any time at any inpatient or outpatient clinic part of the system's database, this is a firm, if possibly underestimated, number. The underestimate recognizes that there are some who are undiagnosed and not receiving treatment at all, or who are seen by a family physician but never by a mental health inpatient or outpatient facility. Nevertheless, this precise determination of the prevalence of schizophrenia is the most accurate count available and became a basis for the subsequent calculations in the effort to determine with greater precision the housing needs of persons disabled by mental illness who live in a midsized North American urban area.

Although there are differences, Calgary shares many demographic and economic similarities with comparable Canadian and U.S. cities [48]. In addition, Canadian rates of prevalence of mental disorders and service delivery systems are comparable to that in the United States [45, 49, 50]. A report by the Public Health Agency of Canada suggests that, due to demographic similarities, public health officials in Canada can utilize American data to estimate national prevalence of mental illnesses in Canada [12]. Thus it is reasonable to conclude that the approach to determining housing need outlined below will inform housing planners and policy makers in determining housing development for low income and marginalized persons disabled by serious mental illnesses.

An extensive literature search, including grey literature and government documents, failed to uncover any population-based determination of housing need for persons with MID. A detailed report estimated housing need for adults with severe addiction and/or a mental illness but limited its focus to persons with additional severe substance abuse and focused only on those who were at housing risk or absolutely homeless (absolute homelessness refers primarily to those who are sleeping without shelter (on the street or park benches) and sometimes includes those who are sleeping in emergency shelters. A variety of synonyms for this term are used globally including "literally homeless," "roofless," or "houseless"). That report, based on a combination of one-year prevalence studies and estimates derived from local experts relies heavily on "expert opinion" and yields questionably large estimates of housing need. We encountered a similar dilemma when we turned first to examine homeless counts and estimates of the homeless population disabled by a mental illness. As explained below, using homeless counts skews results because many homeless are not disabled by a mental illness, and many of those mentally ill are among the hidden homeless, whose numbers are vague and not well documented (Method 1, below). We therefore developed a second approach (Method 2), using disability and prevalence data, which provided more accurate results, when compared with a well-documented benchmark of the known prevalence of schizophrenia in the Calgary region.

\section{Assessing the Housing Needs of People with Severe Mental Illness: Two Approaches}

4.1. Method 1: The Homeless Mentally Ill: Absolutely and Hidden Homeless. Assessing the number of people with MID based on data about the homeless population underestimates this group. Reports, such as those published by the Department of Housing and Urban Development (HUD) in the U.S. and the Calgary Homeless Foundation (CHF), count shelter users but not those considered to be among the hidden homeless-people doubled up and couch surfing. Data from the U.S. [51] and Canada [52] calculated the number of absolutely homeless to be similar in both countries at approximately $20-25 \%$ of the total (hidden and absolute) homeless population.

Data from the Calgary 2008 homeless count, a reasonably accurate count of the absolutely homeless, produced a homeless count of 4060 , of which $28 \%$ (1136) are estimated to have a severe mental illness $[53,54]$. This number is in line with an incidence rate of $26.2 \%$ reported in the most recent HUD report [55]. This includes those who are dually diagnosed (cooccurring mental illness and substance abuse), but not those whose primary problems are substance abuse. Using these estimates, applied to Calgary, produces the following:

absolutely homeless: 4060

absolutely homeless with mental illness $(4060 \times 28 \%)$ : 1136

hidden homeless $(4060 \times 4)$ : 16240

hidden homeless with mental illness $(16240 \times 28 \%)$ : 4547

total homeless with mental illness: 5683.

There are a few challenges with this method which prevent establishment of validity for the calculations. Using homeless counts to estimate need can be problematic as precise counts are elusive, especially for the hidden homeless population, for whom estimates of the prevalence of mental illness are not well documented. An additional concern relates to existing and well-established data on prevalence of certain 
mental illnesses among the general population. Since the total presented in Method 1 is well below the prevalence of schizophrenia reported by Benzins and Guyn [44], which also does not include those with other diagnoses, it is clearly a serious underestimate of persons disabled by mental illness who require assistance with obtaining affordable housing and ancillary supports. This leads to Method 2 which, based on prevalence data, can provide more reliable results.

4.2. Method 2: Disability and Prevalence Calculation. The second approach is a synthetic analysis based on population prevalence and disability information which involves the use of existing, confirmed information from several sources to extrapolate the target data. A synthetic analysis was recently used to estimate need for mental health services [56] and estimates of county-wide mental health professional supply at the county level in the U.S. [57], using data that does not include those diagnosed with schizophrenia.

The justification for the approach presented here, which uses prevalence of schizophrenia as foundational to the calculations, is multifold: persons with schizophrenia are very likely to be disabled and require housing with supports (e.g., [46]); there is a large body of evidence about the incidence and prevalence of schizophrenia; the evidence on disability for those with schizophrenia is widely documented [47]; since we had access to accurate prevalence data on those with schizophrenia in the Calgary region, we could have confidence in the basis of our calculations; finally, large-scale studies also supply reliable information on the proportion of those with schizophrenia and other disorders in existing housing. These various sources of information were used to determine the relative proportion of persons with schizophrenia and other disorders requiring housing.

4.2.1. Prevalence of Mental Illness. Prevalence rates for schizophrenia have been documented by Canadian [58], US [46], and international [59] bodies and in numerous academic studies [60]. These rates vary from $.3 \%$ to $2 \%$ of the population depending on where and how data was collected and where in the world (urban, rural, cold, or hot climate) the research was done $[61,62]$. Because of this variability, Goldner and colleagues [60] recommended that "local rates, whose demographic structure most closely matches local population" (page 833) be used by health planners. This recommendation, however, presumes that strong, reliable prevalence data is difficult, if not impossible to obtain. We were able to access prevalence data on schizophrenia that are very robust and underpin the analysis that we have developed.

A study which determined a prevalence of 6841 of those diagnosed with schizophrenia in the Calgary health region [44] was based on reported diagnoses made by all treating physicians and mental health services. Since this health region services all residents in the Calgary area under a universal health care system and thus a unified electronic data system of all persons served, it provides a reasonably accurate count of those diagnosed. While private practitioners and some nonprofit agencies provide counselling that is not included in the health system data base, all physician-related services are covered in this study. Researchers report a rate of .08 per thousand, based on a population of 855,400 adults between the ages of 18-65 [63]. Although this study may have missed some untreated individuals, it is as accurate indication of the prevalence of schizophrenia as can be obtained anywhere. Moreover, it falls within the range reported elsewhere using other measurement approaches.

4.2.2. Mental Illness and Disability. A considerable proportion of the work on mental illness and disability using large epidemiological databases comes from the U.S. [46]. There is considerable agreement that schizophrenia causes disability [64-68]; but there is far less concurrence as to the extent of this disability or the percentage of persons who are sufficiently, partially, or totally disabled by the disease that they are unable to work in competitive employment. Documentation on the proportion of those with schizophrenia as opposed to other disabling conditions is also not readily identifiable.

Several studies have investigated the effects of mental illness on employment and work disability [67, 69]. Employability is significant for two reasons: those relying on income assistance programs do not have the resources to afford competitive housing and full-time competitive employment that would put market housing in reach is not attainable by most disabled by a mental illness. Jans and colleagues [46], in an analysis of symptoms and program participation, report that over two-thirds of all persons with a mental illness have a disability. However, they indicate that the rate of disability changes according to severity and chronicity of illness. In another study, the disability rate for schizophrenia is reported to be between 70 and $80 \%$ of the population [70]. In keeping with an intentional moderate approach, we chose the lower rate of $70 \%$ in order to develop a conservative estimate of the population with schizophrenia disabled by their mental illness which would require supported housing. While there are many persons disabled by mental illness who continue to receive housing supports from parents and family members, this is not a long-term solution for everyone and, as parents age, is increasingly a diminishing option for many $[71,72]$.

\subsubsection{Proportion of People with Various Diagnoses in Sup-} ported Housing. Disabling mental illnesses span a number of disorders in addition to schizophrenia and the literature did not provide information on the proportion of those with MID who have disorders other than schizophrenia and are disabled to the extent that they require housing and other financial and instrumental supports. Several studies on supportive housing provide some guidelines for the relative proportion of those with schizophrenia and other mental illness living in supportive housing. We examined the results of major housing studies in the field of mental health that had subject populations ranging from 2,939 to 5395 persons $[73,74]$ along with one report of a meta-analysis of 17 housing studies [75] and a recently completed study of housing first in five Canadian cities $[8,76]$.

The Lipton et al. study reported that $53 \%$ of their participants were diagnosed with schizophrenia while the Mares \& Rosenheck study reported 50\% with another 7\% have 
"other psychotic" disorders. Newman reviewed studies which reported a diagnosis of schizophrenia with a mode of 55\% of the total population of the studies. The report by Goering and colleagues included 2149 absolutely homeless individuals who have histories of both mental illnesses and co-occurring addictions and reported an overall rate of psychotic disorders in $51.3 \%$ of the participants. These rates, from diverse sources, fall within $5 \%$ of each other in the proportion of persons with schizophrenia and psychotic disorders and this provides a fairly consistent prevalence for comparison across North American urban centers. Using these rates we established the proportion of those with schizophrenia and other disorders in a city of a million people (Calgary), where 855,400 individuals are identified as adults between the ages of 18-65.

A detailed examination of these studies' use of diagnostic data indicated that the mode of 55\% across all studies was most representative of the prevalence of a diagnosis of schizophrenia across housing programs. Thus on average, $45 \%$ of residents in these supported housing programs for persons with mental illness have other psychiatric diagnoses. We used these proportions to calculate the variable $Y_{o}$ (proportion of persons with other diagnoses) in the equation described below.

4.2.4. Calculating the Need. While acknowledging the numerous complexities that exist in the fields of mental illness, housing, and supports, we opted to use a parsimonious approach to determining need based on Ockham's razor [77]. This principle advocates that the least complex approach to a situation that yields strong results is the preferred method. A simple methodology that had rigorous application is preferable for policy analysts and social planners. We developed a formula to calculate need for those disabled by serious mental illnesses that was based on the following considerations. It included the approximate number of people who were disabled by schizophrenia $\left(Y_{s}\right)$, plus the approximate number of people disabled by other psychiatric diagnoses $\left(Y_{o}\right)$, and then considered the representation of these two groups in terms of their proportion of the total population of persons with mental illness. This proportion was derived by triangulating the information on the prevalence of those with schizophrenia, the proportion disabled by schizophrenia $\left(P_{s}\right)$, and those disabled with other psychiatric diagnoses $\left(P_{o}\right)$, derived from ratios of residents in supported housing and thus to calculate the total prevalence of those disabled $(X)$ and in need of housing. The following formula was derived, using the preceding information, to estimate the housing needs of people with severe mental illness:

$$
X=Y_{s}+Y_{o}
$$

$X=$ total prevalence of those disabled by a serious mental illness per 1000,000 (and therefore in need of housing), $Y_{s}$ $=$ number of persons disabled by schizophrenia per 100,000, where $Y_{s}$ is calculated at $.08 \%$ of the adult population, and $70 \%$ of those with schizophrenia as disabled, $Y_{o}=$ number of persons disabled by other psychiatric diagnoses per 100,000, where $Y_{o}=Y_{s} \times P_{s}(45 \%) / P_{o}(55 \%), P_{s}=$ proportion of people disabled by schizophrenia currently in supported housing (45\%), and $P_{o}=$ proportion of people disabled by other psychotic and mood disorders currently in supported housing (55\%).

Using Calgary as an example, we illustrate how housing need is calculated based on a population of one million, where 855,400 individuals are identified as adults between the ages of 18-65:

$$
Y_{s}=4790
$$

$(855,400 \times .08 \%=6843$ people with schizophrenia in Calgary $\times 70 \%$ of these people disabled)

$$
Y_{o}=4790 \times \frac{45}{55}=3919
$$

and thus the total housing unit needs

$$
X=4790+3919=8709 .
$$

When we apply this formula to the proportions of those who have a diagnosis of schizophrenia or another disorder as cited by the housing studies used to determine the ratio of types of mental illness diagnoses among the housed [73-75], we have a range of need from 8707 to 9571 . This averages to 9139 beds and the average falls within a range of $\pm 5 \%$ of the upper and lower limits calculated. In other words, the range and the average is within acceptable limits. Coordination of homeless and mental health services in Calgary allows for an accurate count of beds available to mental health consumers, including those with concurrent disorders, which currently totals 1550 [78]. This indicates a gap of between 7157 and 8021 , or an average of 7589 housing units for persons with MID. Thus Calgary meets the needs of less than $20 \%$ of those disabled by mental illness.

\section{Discussion}

Several important observations emerge from this needs calculation. As with the needs assessments for mental health personnel in the U.S. [56, 57], our calculations also point to a large gap between needed and available services. Suitable, stable housing for those disabled by mental illness promotes mental and physical health and wellbeing [79-81]. Lack thereof leads to increasing disability and poor health and places inordinate demands on the social services and health care sectors $[82,83]$.

We recognize that there remains a lack of precision in these estimates, but the simplicity of the recommended approach to estimating need lends itself to rapid application in various geographical locations. In using these rates, there is the explicit assumption that the proportion of people with various disorders currently in supported housing reflects the proportion of people disabled by mental illnesses in the population. It may be argued that, in these studies, those in housing are more disabled than their counterparts who were not in supported housing. However, the aim, to determine the proportion of those disabled, would apply across all diagnostic categories.

The methodology may be flawed by the assumptions that have been made about the proportion of those disabled 
by other mental illnesses, although the range reported in the housing studies varies by only $10 \%$. Their concurrence suggests that there is some justification in the assumption that between $50 \%$ and $55 \%$ of those who need supportive housing have a diagnosis other than schizophrenia. Alternatively, if calculations are made based on the disability work by Jans et al. [46], the assessed need we report would be an underestimate; likewise, using homeless counts results in a large underreporting.

We place a justified reliance on the accuracy of the prevalence of schizophrenia in Calgary reported by Benzins and Guyn [44]. There is no other data available anywhere which determines prevalence of schizophrenia that uses a single, large health care system where all users are accounted for in a single database. The accuracy of this cornerstone data base in validating the proposed formula is of pivotal importance. Regional variation in the prevalence of schizophrenia, one the basis of these calculations, will influence outcomes. A final caution is that these numbers do not include persons whose primary diagnosis is severe substance abuse, those who have a co-occurring developmental disability, or youth under the age of 18 since these persons are not usually included in schizophrenia and other mental disorder prevalence rates [84]. What is apparent is that even conservative estimates indicated by these calculations will yield large gaps between availability and need.

These estimates do not address the additional issues of the types of housing and supports required, and they only indicated that a substantial number of disabled persons require housing that has here-to-fore not been publicly acknowledged, in ways that needs for hospitals, schools, and roads are forecast. While considerable attention has recently been devoted to "housing first" models and their efficacy for those with serious mental illness and co-occurring substance abuse disorders $[85,86]$, this approach may not be suitable for everyone [87]. Other models, including boarding homes, family style homes, and skilled nursing facilities, are needed to serve those severely disabled or with concurrent medical problems [88]. While housing first models may support many who have traditionally been placed in more restrictive levels of care, this study and similar ones [85] do not address this issue of determining need before examining the degree of independent living for specialized subpopulations.

This process has identified several important planning issues. Most housing and mental health authorities have an inadequate and understated estimate of housing need and supports that should be made available for vulnerable people with MID who are at high risk for rehospitalisation or homelessness. Critics may raise the issue that not all persons with MID are currently homeless, on the streets, or in shelters. At the present time, they are among the millions included in the hidden homeless-doubled up or couch surfing with family and friends, living in overcrowded and unsafe housing [89]. In addition, anecdotal reports and those describing the hidden homeless indicate that a sizable cohort with MID reside in the basement recreation rooms, apartments, or converted garages owned by family members. While a few are married and supported by spouses and others manage independence through having been bequeathed housing by deceased relatives, in those location where homeownership does not preclude receiving disability assistance income, most are at the behest of others and in many instances this is a tenuous situation subject to the vagaries of life: illness of caregivers, death, and breakdown of relationships [90].

As with other forms of hidden homelessness, there is no firm data to support the extent to which these forms of housing (with family members) are available to those with MID or to suggest whether these options are preferred or are a last resort. What is clear is that Calgary, a typical Canadian city with an average level of social service system supports, provides significantly less support for those with MID than estimates suggest is needed. This lack of availability of appropriate housing and supports and failure to plan is ubiquitous across America and is symptomatic of the failure to gauge the extent of those with MID who need housing and supports. The size of this cohort and their specifically tailored needs remains a topic for further challenging research as they are difficult to locate and have received little attention in the literature. An examination of the housing arrangements and their stability for those with MID and their caregivers is of timely importance.

\section{Conclusions}

Historically, the provision of community housing for persons with mental illness was initiated with the advent of deinstitutionalization. At that time, little thought was given to the size of the housing need and what type of housing would be both appropriate and acceptable to those with an MID. Housing type has received considerable attention; housing availability has received fairly little. Debates about fiscal responsibility after deinstitutionalization, with federal, provincial, state, local, health care, and housing sector silos predominating in this discourse, resulted in neglect of proactive planning. Availability, affordability, and acceptability have been the cornerstones with less attention to the sizable gap between what is needed and what is available to those disabled by a mental illness. This report suggests that there is a considerable need for housing units with supports but does not address the attending issue of what format (supportive, cluster or scattersite, congregate care, and institutional care) and how much of these various housing types and locations are necessary to address issues of acceptability and accessibility.

The housing needs of this group of citizens have been obscured by the recent focus on studies that target the homeless population in general and the homeless mentally ill. While those with a mental illness constitute a proportion of the larger homeless group, this analysis does not solely address the housing needs of those absolutely homeless. Rather, it points to a larger, unacknowledged group of people who are not able to afford competitive rental housing, or purchase their own home, and are thus subject to the availability of scant social or subsidized, supported housing resources, or left in substandard accommodation. A substantial group receives shelter from family members. But this resource is tenuous as fragile bonds and caregiver burden, plus an ageing cohort of parent care-takers, pose significant risks for housing 
loss. Thus it becomes imperative that housing and mental health planners closely examine actual numbers of persons with mental illness who need noninstitutional shelter and recognize a small but significant cohort who will need highly specialized care. We hope that this analysis has made a contribution.

\section{Conflict of Interests}

The authors declare that there is no conflict of interests regarding the publication of this paper.

\section{References}

[1] S. A. McGraw, M. J. Larson, S. E. Foster et al., "Adopting best practices: lessons learned in the collaborative initiative to help end chronic homelessness (CICH)," Journal of Behavioral Health Services and Research, vol. 37, no. 2, pp. 197-212, 2010.

[2] M. J. Rice, "Assertive community treatment: evidence based hope for the seriously mentally ill," Journal of the American Psychiatric Nurses Association, vol. 17, no. 1, pp. 13-15, 2011.

[3] S. Tsemberis, "Housing first: ending homelessness and transforming lives," Schizophrenia Research, vol. 117, no. 2-3, pp. 163164,2010 .

[4] C. Forchuk, R. Csiernik, and E. Jennsen, Homelessness, Housing and Mental Health, Canadian Scholars' Press, 2011.

[5] C. Forchuk, G. Russell, S. Kingston-Macclure, K. Turner, and S. Dill, "From psychiatric ward to the streets and shelters," Journal of Psychiatric and Mental Health Nursing, vol. 13, no. 3, pp. 301308, 2006.

[6] C. J. Frankish, S. W. Hwang, and D. Quantz, "The relationship between homelessness and health: an overview of research in Canada," in Finnding Home: Public Options for Addressing Homelessness in Canada, D. Hulchanski, P. Campsie, S. Chhhhau, S. Hwang, and E. Paradis, Eds., pp. 2-21, Homeless HUB, Toronto, Canada, 2009.

[7] M. B. DeSilva, J. Manworren, and P. Targonski, "Impact of a housing first program on health utilization outcomes among chronically homeless persons," Journal of Primary Care \& Community Health, vol. 2, no. 1, pp. 16-20, 2011.

[8] S. W. Hwang, V. Stergiopoulos, P. O'Campo, and A. Gozdzik, "Ending homelessness among people with mental illness: the At Home/Chez Soi randomized trial of a Housing First intervention in Toronto," BMC Public Health, vol. 12, article 787, no. 1, 2012.

[9] V. Stergiopoulos, C. Dewa, G. Tanner, N. Chau, M. Pett, and J. Connelly, "Addressing the needs of the street homeless: a collaborative approach," International Journal of Mental Health, vol. 39, no. 1, pp. 3-15, 2010.

[10] S. Tsemberis, D. Kent, and C. Respress, "Chronically homeless persons with co-occuring disorders in Washington, DC," American Journal of Public Health, vol. 102, no. 1, pp. 13-16, 2012.

[11] E. F. Torrey, Nowhere to Go: The Tragic Odyssey of the Homeless Mentally Ill, Harper \& Row, New York, NY, USA, 1988.

[12] Public Health Agency Canada, "The human face of mental health and mental illness in Canada 2006," 2014, http://www .phac-aspc.gc.ca/publicat/human-humain06/14-eng.php.

[13] G. Nelson, T. Aubry, and A. Lafrance, "A review of the literature on the effectiveness of housing and support, assertive community treatment, and intensive case management interventions for persons with mental illness who have been homeless," American Journal of Orthopsychiatry, vol. 77, no. 3, pp. 350-361, 2007.

[14] C. Wong, Indicators for Urban and Regional Planning: The Interplay of Policy and Methods, Routledge, 2013.

[15] S. J. Newman, J. D. Reschovsky, K. Kaneda, and A. M. Hendrick, "The effects of independent living on persons with chronic mental illness: an assessment of the Section 8 certificate program," The Milbank Quarterly, vol. 72, no. 1, pp. 171-198, 1994.

[16] S. Saha, D. Chant, J. Welham, and J. McGrath, "A systematic review of the prevalence of schizophrenia," PLoS Medicine, vol. 2, no. 5, article el41, 2005.

[17] Social Security Administration, "State assistance programs for SSI recipients, January 2011," 2011.

[18] O. Massey and L. Wu, "Important characteristics of independent housing for people with mental illness: perspectives of case managers and consumers," Psychosocial Rehabilitation Journal, vol. 17, no. 2, pp. 81-92, 1993.

[19] S. S. L. Sohng, "Supported housing for the mentally ill elderly: implementation and consumer choice," Community Mental Health Journal, vol. 32, no. 2, pp. 135-148, 1996.

[20] M. F. Brunette, K. T. Mueser, and R. E. Drake, "A review of research on residential programs for people with severe mental illness and co-occurring substance use disorders," Drug and Alcohol Review, vol. 23, no. 4, pp. 471-481, 2004.

[21] G. W. Evans, N. M. Wells, and A. Moch, "Housing and mental health: a review of the evidence and a methodological and conceptual critique," Journal of Social Issues, vol. 59, no. 3, pp. 475-500, 2003.

[22] S. J. Newman, And Mental Illness: A Critical Review of the Literature, The Urban Institute, Washington, DC, USA, 2001.

[23] P. J. Carling, "Homes or group homes? Future approaches to housing, support, and integration for people with psychiatric disabilities," Adult Residential Care Journal, vol. 6, no. 2, pp. 8796, 1992.

[24] P. J. Carling, Return to Community: Building Support Systems for People with Psychiatric Disabilities, Guildford Press, New York, NY, USA, 1995.

[25] P. Ridgeway and C. A. Rapp, The Active Ingredients of Effective Supported Housinig: A Research Synthesis, The University of Kansas, Lawrence, Kan, USA, 1997.

[26] G. Lambert, P. Ricci, R. Harris, and F. Deane, "Housing needs of consumers of mental health services in rural New South Wales, Australia," International Journal of Social Psychiatry, vol. 46, no. 1, pp. 57-66, 2000.

[27] F. L. Randolph, R. E. Lindenberg, and A. Z. Menn, "Residential facilities for the mentally ill: needs assessment and community planning," Community Mental Health Journal, vol. 22, no. 2, pp. 77-89, 1986.

[28] C. Owen, V. Rutherford, M. Jones, C. Wright, C. Tennant, and A. Smallman, "Housing accommodation preferences of people with psychiatric disabilities," Psychiatric Services, vol. 47, no. 6, pp. 628-632, 1996.

[29] R. K. Schutt and S. M. Goldfinger, "Housing preferences and perceptions of health and functioning among homeless mentally ill persons," Psychiatric Services, vol. 47, no. 4, pp. 381386, 1996.

[30] J. Harkness, S. J. Newman, and D. Salkever, "The cost-effectiveness of independent housing for the chronically mentally ill: do housing and neighborhood features matter?" Health Services Research, vol. 39, no. 5, pp. 1341-1360, 2004. 
[31] T. Peressini, L. McDonald, and D. Hulchanski, Estimating Homelessness: Towards a Methodology for Counting the Homeless in Canada, Canada Mortgage and Housing Corporation, Toronto, Canada, 1995.

[32] K. Hopper and S. M. Barrow, "Two genealogies of supported housing and their implications for outcome assessment," Psychiatric Services, vol. 54, no. 1, pp. 50-54, 2003.

[33] G. Nelson, G. B. Hall, and C. Forchuk, "Current and preferred housing of psychiatric consumers/survivors," Canadian Journal of Community Mental Health, vol. 22, no. 1, pp. 5-19, 2003.

[34] S. Tsemberis and R. F. Eisenberg, "Pathways to housing: supported housing for street-dwelling homeless individuals with psychiatric disabilities," Psychiatric Services, vol. 51, no. 4, pp. 487-493, 2000.

[35] R. Bunker, D. Holloway, and B. Randolph, "Building the connection between housing needs and metropolitan planning in Sydney, Australia," Housing Studies, vol. 20, no. 5, pp. 771-794, 2005.

[36] K. L. Thomas and C. Mccormack, "Adequate housing for people with a serious mental illness: policy obstacles and practice solutions," Australasian Psychiatry, vol. 7, no. 2, pp. 81-84, 1999.

[37] J. Waegemakers Schiff, B. Schneider, and R. Schiff, Housing Needs in the Calgary Region for Persons with Severe and Persistent Mental Illness, Calgary Homeless Foundation, Mental Health Sector, Calgary, Canada, 2007.

[38] L. F. Heumann, "Assessing the quality of local housing needs analyses," Review of Public Data Use, vol. 6, no. 2, pp. 13-23, 1978.

[39] I. S. Levine and J. Parrish, "Comments on residential facilities for the mentally ill: needs assessment and community planning," Community Mental Health Journal, vol. 22, no. 2, pp. 9093, 1986.

[40] Substance Abuse and Mental Health Service Administration (SAMHSA), National Household Survey on Drug Abuse, 2000 and 2001, SAMSHA, Rockville, Md, USA, 2001.

[41] H. J. Steadman, F. C. Osher, P. C. Robbins, B. Case, and S. Samuels, "Prevalence of serious mental illness among jail inmates," Psychiatric Services, vol. 60, no. 6, pp. 761-765, 2009.

[42] D. P. Folsom, W. Hawthorne, L. Lindamer et al., "Prevalence and risk factors for homelessness and utilization of mental health services among 10,340 patients with serious mental illness in a large public mental health system," American Journal of Psychiatry, vol. 162, no. 2, pp. 370-376, 2005.

[43] P. J. Martens, R. Fransoo, E. Burland, C. Burchill, H. J. Prior, and O. Ekuma, "Prevalence of mental illness and its impact on the use of home care and nursing homes: a population-based study of older adults in Manitoba," Canadian Journal of Psychiatry, vol. 52, no. 9, pp. 581-590, 2007.

[44] S. Benzins and L. Guyn, "Schizophrenia service utilization patterns in Calgary," in Proceedings of the World Psychiatric Organization, Epidemiology and Public Health Sector Meeting, Saskatoon, Canada, 2008.

[45] Public Health Agency of Canada, "A report on mental ilnessess in Canada," 2014, http://www.phac-aspc.gc.ca/publicat/miicmmac/chap_1-eng.php\#footnote2.

[46] L. Jans, S. Stoddard, and L. Kraus, "Chartbook on mental health and disability in the United States," An InfoUse Report, 2004, http://www.infouse.com/disabilitydata/mentalhealth/credits .php.

[47] F. R. Leifker, C. R. Bowie, and P. D. Harvey, "Determinants of everyday outcomes in schizophrenia: the influences of cognitive impairment, functional capacity, and symptoms," Schizophrenia Research, vol. 115, no. 1, pp. 82-87, 2009.
[48] K. England and J. Mercer, "Canadian cities in continental context: global and continental perspectives on Canadian urban development," in Canadian Cities in Transition: Local Through Global Perspectives, vol. 3, pp. 24-39, 2006.

[49] National Institute of Mental Health, The Numbers Count: Mental Disorders in America, NIMH, Rockville, Md, USA, 2014, http: //www.nimh.nih.gov/health/publications/the-numbers-countmental-disorders-in-america/index.shtml\#Schizophrenia.

[50] R. P. Olson, Mental Health Systems Compared: Great Britain, Norway, Canada, and the United States, Charles C Thomas Publisher, 2006.

[51] National Alliance to End Homelessness, Data Snapshot: Doubled-Up in the United States, National Alliance to End Homelessness, Washington, DC, USA, 2007.

[52] S. Gaetz, J. Donaldson, T. Richter, and T. Gulliver, The State of Homelessness in Canada 2013, Canadian Homelessness Research Network Press, Toronto, Canada, 2013.

[53] H. Gardiner and K. Cairns, 2002 Calgary Homeless Study, Mental Health Sector Report, Calgary Homeless Foundation, Calgary, Canada, 2003.

[54] P. Goering, G. Tolomiczenko, T. Sheldon, K. Boydell, and D. Wasylenki, "Characteristics of persons who are homeless for the first time," Psychiatric Services, vol. 53, no. 11, pp. 1472-1474, 2002.

[55] Department of Housing and Urban Development (HUD), The 2010 Annual Homeless Assessment Report to Congress, HUD, Washington, DC, USA, 2011.

[56] T. R. Konrad, A. R. Ellis, K. C. Thomas, C. E. Holzer, and J. P. Morrissey, "County-level estimates of need for mental health professionals in the United States," Psychiatric Services, vol. 60, no. 10, pp. 1307-1314, 2009.

[57] A. R. Ellis, T. R. Konrad, K. C. Thomas, and J. P. Morrissey, "County-level estimates of mental health professional supply in the United States," Psychiatric Services, vol. 60, no. 10, pp. 13151322, 2009.

[58] J. Dunn, The Population Health Approach to Housing: A Framework for Research, Canada Mortgage and Housing Corporation, Ottawa, Canada, 2002.

[59] WHO, Dollars, DAYLS and Decisions: Economic Aspects of the Health System, 2006.

[60] E. M. Goldner, L. Hsu, P. Waraich, and J. M. Somers, "Prevalence and incidence studies of schizophrenic disorders: a systematic review of the literature," Canadian Journal of Psychiatry, vol. 47, no. 9, pp. 833-843, 2002.

[61] D. K. Kinney, P. Teixeira, D. Hsu et al., "Relation of Schizophrenia prevalence to latitude, climate, fish consumption, infant mortality, and skin color: a role for prenatal vitamin D deficiency and infections?" Schizophrenia Bulletin, vol. 35, no. 3, pp. 582-595, 2009.

[62] J. McGrath, S. Saha, J. Welham, O. El Saadi, C. MacCauley, and D. Chant, "A systematic review of the incidence of schizophrenia: the distribution of rates and the influence of sex, urbanicity, migrant status and methodology," BMC Medicine, vol. 2, article 13, 2004.

[63] City of Calgary, Affordable Housing Calgary Fast Facts \#2: Definitions Related to Homelessness, City of Calgary, Calgary, Canada, 2004.

[64] C. R. Bowie, A. Reichenberg, T. L. Patterson, R. K. Heaton, and P. D. Harvey, "Determinants of real-world functional performance in schizophrenia subjects: correlations with cognition, functional capacity, and symptoms," American Journal of Psychiatry, vol. 163, no. 3, pp. 418-425, 2006. 
[65] A. Cougnard, R. Goumilloux, F. Monello, and H. Verdoux, "Duration and characteristics of the period between onset of schizophrenia and first request for disability status," Schizophrenia Research, vol. 98, supplement, pp. 68-68, 2008.

[66] V. Villalta-Gil, M. Vilaplana, S. Ochoa et al., "Neurocognitive performance and negative symptoms: are they equal in explaining disability in schizophrenia outpatients?" Schizophrenia Research, vol. 87, no. 1-3, pp. 246-253, 2006.

[67] T. H. Jobe and M. Harrow, "Schizophrenia course, longterm outcome, recovery, and prognosis," Current Directions in Psychological Science, vol. 19, no. 4, pp. 220-225, 2010.

[68] M. Harrow, L. S. Grossman, T. H. Jobe, and E. S. Herbener, "Do patients with schizophrenia ever show periods of recovery? A 15-year multi-follow-up study," Schizophrenia Bulletin, vol. 31, no. 3, pp. 723-734, 2005.

[69] R. V. Bijl and A. Ravelli, "Current and residual functional disability associated with psychopathology: findings from the Netherlands mental health survey and incidence study (NEMESIS)," Psychological Medicine, vol. 30, no. 3, pp. 657-668, 2000.

[70] M. Harrow, J. R. Sands, M. L. Silverstein, and J. F. Goldberg, "Course and outcome for schizophrenia versus other psychotic patients: a longitudinal study," Schizophrenia Bulletin, vol. 23, no. 2, pp. 287-303, 1997.

[71] K. A. Aschbrenner, J. S. Greenberg, S. M. Allen, and M. M. Seltzer, "Subjective burden and personal gains among older parents of adults with serious mental illness," Psychiatric Services, vol. 61, no. 6, pp. 605-611, 2010.

[72] C.-Y. Hsiao and M. van Riper, "Research on caregiving in chinese families living with mental illness: a critical review," Journal of Family Nursing, vol. 16, no. 1, pp. 68-100, 2010.

[73] F. R. Lipton, C. Siegel, A. Hannigan, J. Samuels, and S. Baker, "Tenure in supportive housing for homeless persons with severe mental illness," Psychiatric Services, vol. 51, no. 4, pp. 479-486, 2000.

[74] A. S. Mares and R. A. Rosenheck, "One-year housing arrangements among homeless adults with serious mental illness in the ACCESS Program," Psychiatric Services, vol. 55, no. 5, pp. 566574, 2004.

[75] S. J. Newman, "Housing attributes and serious mental illness: implications for research and practice," Psychiatric Services, vol. 52, no. 10, pp. 1309-1317, 2001.

[76] P. Goering, S. Veldhuizen, A. Watson et al., At Home/Chez Soi Interim Report, Mental Health Commission of Canada, Calgary, Canada, 2012.

[77] W. H. Jefferys and J. O. Berger, "Ockham's razor and Bayesian analysis," in American Scientist, pp. 64-72, 1992.

[78] B. Schneider, J. Ali, L. Arney et al., "Housing for people living with schizophrenia," Draft publication.

[79] T. W. Kallert, M. Leisse, and P. Winiecki, "Comparing the effectiveness of different types of supported housing for patients with chronic schizophrenia," Journal of Public Health, vol. 15, no. 1, pp. 29-42, 2007.

[80] G. Nelson, "Housing for people with serious mental illness," 2007, http://info.wlu.ca/ wwwpsych/gnelson/housing.htm .

[81] S. Newman and H. Goldman, Putting Housing First, Making Housing Last: Housing Policy for Persons with Severe Mental Illness, McArthur Foundation, New York, 2007.

[82] D. P. Folsom, W. Hawthorne, L. Lindamer et al., "Prevalence and risk factors for homelessness and utilization of mental health services among 10,340 patients with serious mental illness in a large public mental health system," American Journal of Psychiatry, vol. 162, no. 2, pp. 370-376, 2005.
[83] K. Jones, P. W. Colson, M. C. Holter et al., "Cost-effectiveness of critical time intervention to reduce homelessness among persons with mental illness," Psychiatric Services, vol. 54, no. 6, pp. 884-890, 2003.

[84] R. C. Kessler and K. R. Merikangas, "The National Comorbidity Survey Replication (NCS-R): background and aims," International Journal of Methods in Psychiatric Research, vol. 13, no. 2, pp. 60-68, 2004.

[85] J. Waegemakers Schiff and J. Rook, Housing First: Where Is the Evidence? Human Resources Development Canada, 2012.

[86] D. K. Padgett, L. Gulcur, and S. Tsemberis, "Housing first services for people who are homeless with co-occurring serious mental illness and substance abuse," Research on Social Work Practice, vol. 16, no. 1, pp. 74-83, 2006.

[87] S. G. Kertesz, K. Crouch, J. B. Milby, R. E. Cusimano, and J. E. Schumacher, "Housing first for homeless persons with active addiction: are we overreaching?” Milbank Quarterly, vol. 87, no. 2, pp. 495-534, 2009.

[88] A. D. Lesage, D. Gélinas, D. Robitaille, É. Dion, D. Frezza, and R. Morissette, "Toward benchmarks for tertiary care for adults with severe and persistent mental disorders," Canadian Journal of Psychiatry, vol. 48, no. 7, pp. 485-492, 2003.

[89] K. Reeve, "The hidden truth about homelessness," Crisis, CRESR, 2011.

[90] B. A. Lee, K. A. Tyler, and J. D. Wright, “The new homelessness revisited," Annual Review of Sociology, vol. 36, pp. 501-521, 2010. 

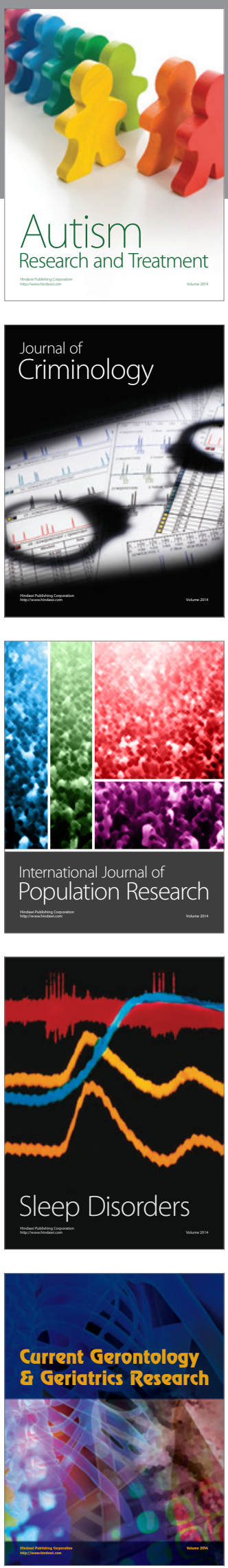
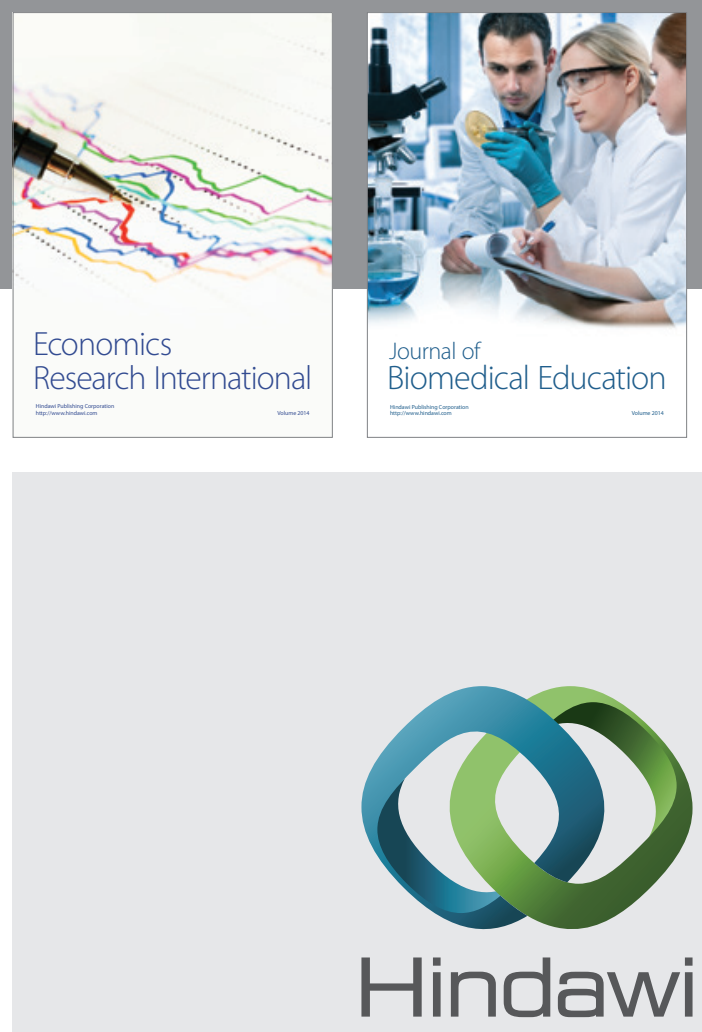

Submit your manuscripts at

http://www.hindawi.com
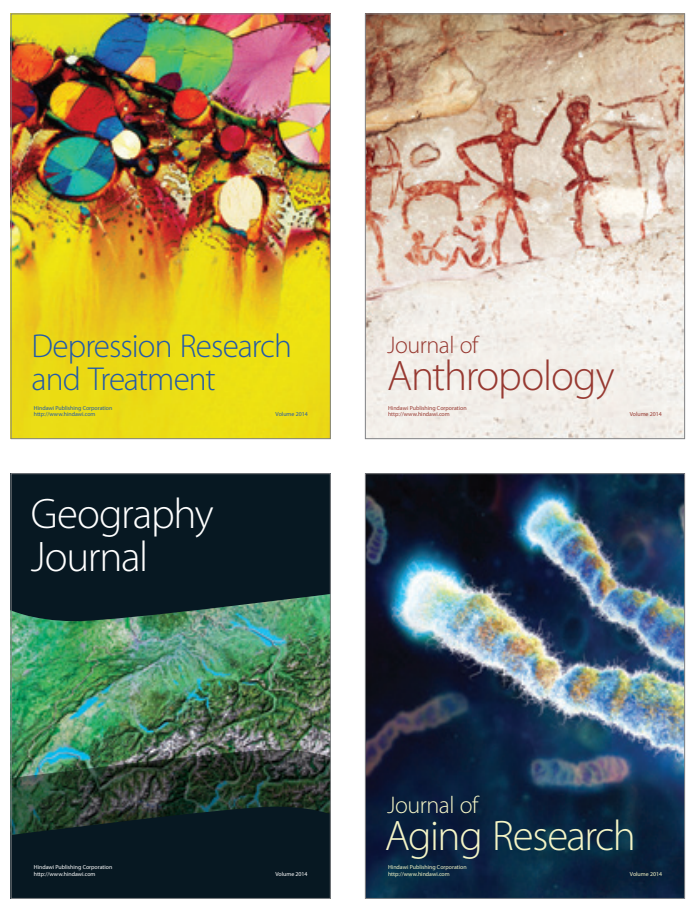
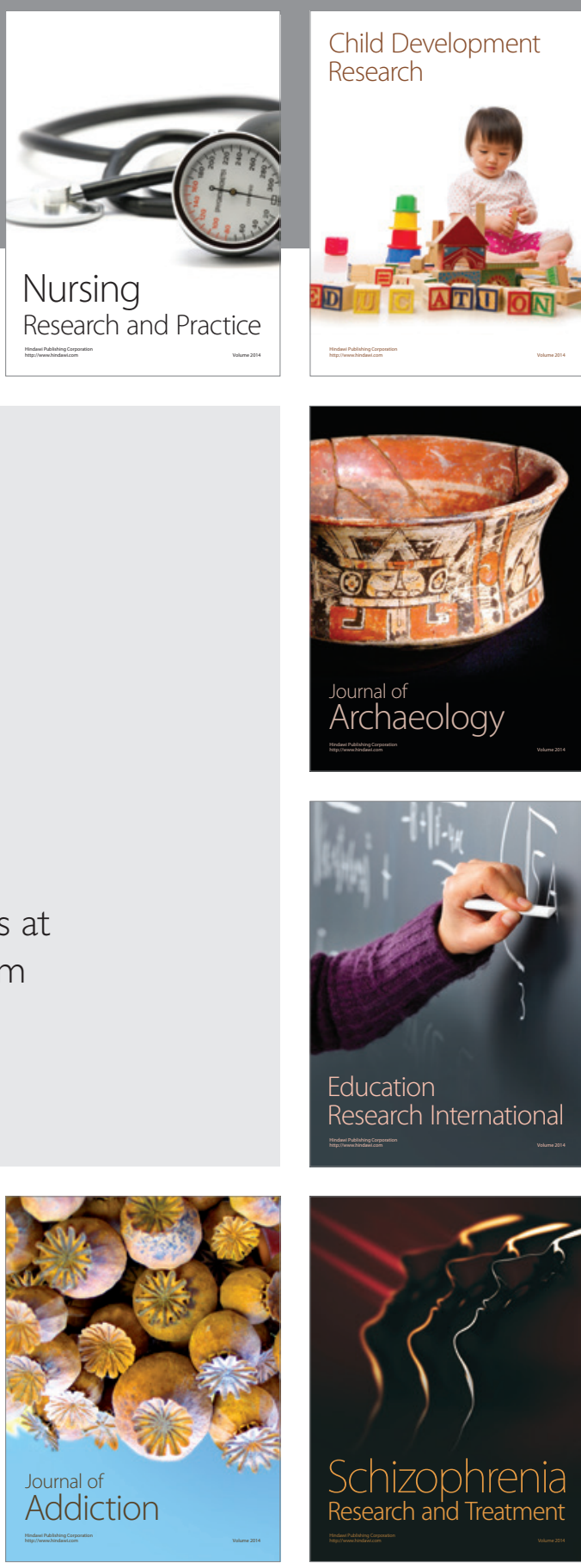

(D)
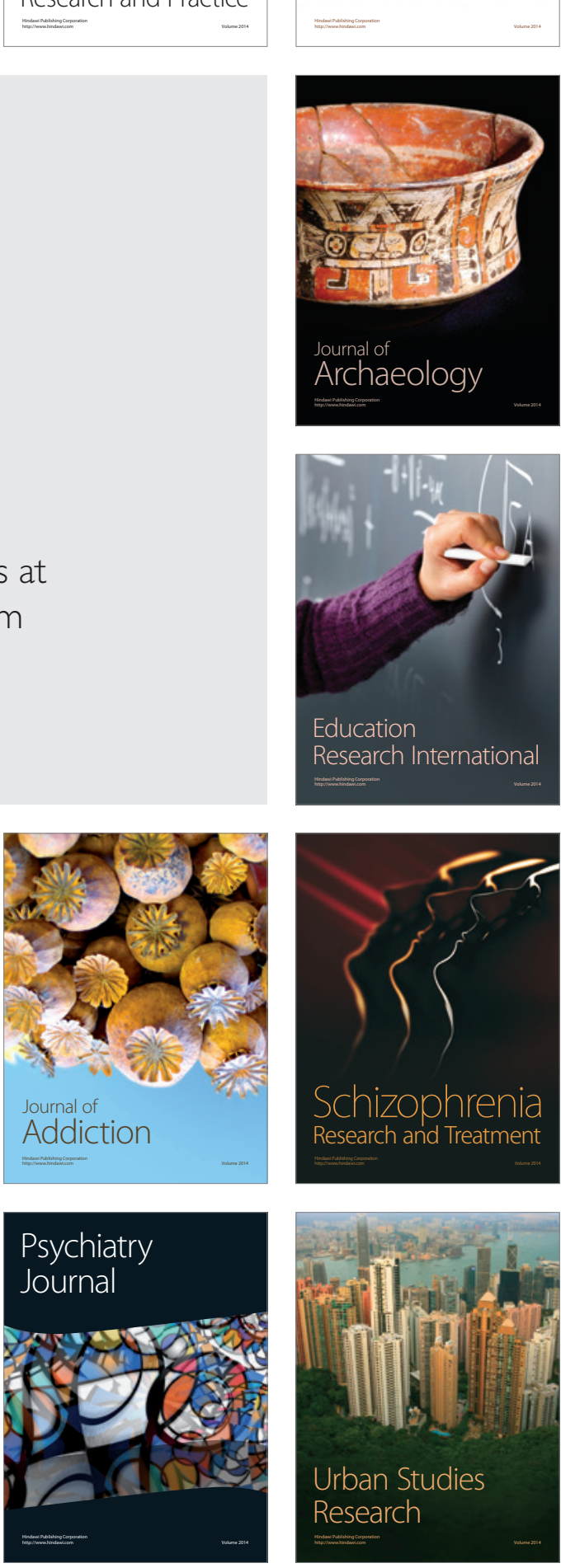